<Commentary on McCullough et al. [Behavioral and Brain Sciences, 35(5), 2012] >

\title{
The fuzzy reality of perceived harms
}

\author{
Sara Konrath $^{\mathrm{a}}$ and Irene Cheung ${ }^{\mathrm{b}}$ \\ ${ }^{\mathrm{a}}$ Research Center for Group Dynamics, Institute for Social Research, Ann Arbor, MI \\ 48104; \\ ${ }^{\mathrm{b}}$ Department of Psychology, The University of Western Ontario, London, Ontario, N6A \\ $5 C 2$, Canada.
}

skonrath@umich.edu_icheung4@uwo.ca

www.sarakonrath.com http://www.wix.com/icheung4/uwo

\begin{abstract}
We review two subjective (mis)perceptions that influence revenge and forgiveness systems. Individual differences predict more (e.g., narcissism) or less (e.g., empathy) revenge, with the opposite pattern for forgiveness. Moreover, differences in victim versus perpetrator perceptions can influence revenge and forgiveness systems, perpetuating never-ending cycles of revenge. These two examples point to the need for theories of revenge and forgiveness to address the role of cognitive and motivational biases in the functionality of such behavioral responses.
\end{abstract}


When it comes to revenge and forgiveness, there is no black and white world where harms are objective. Perceptions matter, whether the misperceptions of individuals who overestimate or underestimate their deservingness of benefits, or misperceptions that stem from the fuzzy nature of "who started it." Such misperceptions can exaggerate harm, and ultimately lead to miscalibrated revenge responses relative to initiating circumstances. Theories of revenge and forgiveness must account for cognitive and motivational processes that serve to inflate or reduce perceptions of harm.

First, what happens when individuals consistently miscalibrate their estimations of others' welfare tradeoff ratios (WTRs) toward the self? Although McCullough et al. touch on the role of individual differences, they mainly focus on ones related to physical strength (e.g., sex), which directly maps onto one's ability to enact revenge. However, individual differences in the propensity toward revenge and forgiveness cannot all be explained this way.

For example, it is likely that people scoring high on the personality trait narcissism overestimate others' WTRs toward themselves, and if so, they would perceive continual violations of these expected WTRs. This would lead to over-active revenge systems to try to increase others' regard for their welfare. Practically, this would manifest itself as increased sensitivity to others' harms to the self, over-reactive anger responses, and a lower likelihood of forgiveness, each of which are correlates of narcissism (Exline et al. 2004; McCullough et al. 2003; Rhodewalt \& Morf 1998). Although in past research males often scored higher than females in narcissism, such sex differences are small and are becoming smaller over time (Twenge et al. 2008). And most research on narcissistic anger and aggression finds that these effects occur independently of sex (Twenge \& Campbell 2003). Thus, narcissists should be likely to see themselves as deserving of unquestioning respect, and to (mis)perceive violations of their expected WTRs, regardless of sex. This rules out the possibility that such individual differences are only explained by the power to successfully enact revenge.

Similarly, people high in dispositional empathy may chronically miscalibrate their WTRs in the opposite direction, and have under-active revenge systems and over-active forgiveness systems (Macaskill et al. 2002; Stuckless \& Goranson 1992). This could make these individuals ripe for potential exploitation, leaving open questions about the evolution of such individual differences. Again, although there are sex differences in selfreported empathy, these differences disappear in physiological measures (Eisenberg \& Lennon 1983; Lennon \& Eisenberg 1989). Thus, it is unlikely that empathy is associated with less revenge and more forgiveness because empathic individuals are less able to successfully enact revenge. A number of other personality variables are also consistently associated with more or less revenge and forgiveness (Mullet et al. 2005).

One way to explain such individual differences in revenge and forgiveness may be to consider the role of interdependence (see sect. 4.2, para. 2). For example, those scoring high in narcissism see themselves as less interconnected and interdependent with others (Konrath et al. 2009), and do not place a high value on relationships (Foster et al. 2006). Thus, they may not be concerned about the relational costs of enacting revenge for 
even minor perceived transgressions. Because they are always on the lookout for new and better relationship partners (Campbell \& Foster 2002; Campbell et al. 2002), the potential to lose current partners might not bother them too much. However, even if this were the case, it would only explain their individual motivations for being overly vengeful, and not the evolutionary function - unless this type of behavior offered them some sort of survival or reproductive advantage.

Other misperceptions are also important to consider. For example, how do differences in victim versus perpetrator perceptions influence revenge and forgiveness systems? Victims and perpetrators do not always see eye-to-eye on the impact of harms, such that victims perceive harms as having continuing implications for their relationships, whereas perpetrators perceive harms as being isolated incidents without long-lasting implications for their relationships (Baumeister et al. 1990; Zechmeister \& Romero 2002). Given such discrepancies in perceptions of harms, victims may retaliate against perpetrators to deter future harms, but these actions may in turn be seen as overreactions or unjust by initial perpetrators, which can ironically lead to feelings of victimization in them. Thus, the roles of the victim and perpetrator can easily reverse and perpetuate cycles of revenge (Schumann \& Ross 2010; Stillwell et al. 2008). In other words, when both parties' perceptions of the harms are not calibrated, revenge cycles may be initiated. McCullough et al. touch on counter-revenge as a cost to revenge and the "echo effect," but more elaboration is needed. When victims and perpetrators are in revenge cycles, how do these cycles end if their actions are driven by (mis)perceptions? What triggers forgiveness in these cycles? Or, at what point do relationships simply dissolve? Also, what is the evolutionary function of revenge cycles?

Victims may seek revenge to change perpetrators' WTRs toward them. However, because perpetrators may also see themselves as victims, they may also try to increase avengers' WTRs toward them. Thus, both victim and perpetrators may feel compelled to increase their retaliation level in order to change WTRs, which can cause irreparable damages to relationships and make it surprising that forgiveness ever occurs at all. Perhaps one function of revenge cycles is to give individuals an opportunity to assess the value of their relationships, so that they can withdraw from potentially unproductive ones (Kearns \& Fincham 2005). That being said, it is also possible that revenge cycles may be more likely to occur after individuals have already decided to dissolve a relationship. In other words, such misperceptions might be more common in the presence of unproductive relationships, and may serve as a catalyst toward dissolution.

We have reviewed two subjective (mis)perceptions that may influence revenge and forgiveness systems, pointing to the need for theories of revenge and forgiveness to address the role of cognitive and motivational biases in the functionality of such behavioral responses. 


\section{References}

Baumeister, R. F., Stillwell, A. \& Wotman, S. R. (1990) Victim and perpetrator accounts of interpersonal conflict: Autobiographical narratives about anger. Journal of Personality and Social Psychology 59(5):994-1005.

Campbell, W. K. \& Foster, C. A. (2002) Narcissism and commitment in romantic relationships: An investment model analysis. Personality and Social Psychology Bulletin 28(4):484-95. doi: 10.1177/0146167202287006

Campbell, W. K., Foster, C. \& Finkel, E. J. (2002) Does self-love lead to love for others? A story of narcissistic game playing. Journal of Personality and Social Psychology 83(2):340-54.

Eisenberg, N. \& Lennon, R. (1983) Sex differences in empathy and related capacities. Psychological Bulletin 94(1):100-31.

Exline, J. J., Baumeister, R. F., Bushman, B. J., Campbell, W. K. \& Finkel, E. J. (2004) Too proud to let go: Narcissistic entitlement as a barrier to forgiveness. Journal of Personality and Social Psychology 87(6):894-912.

Foster, J., Shrira, I. \& Campbell, W. K. (2006) Theoretical models of narcissism, sexuality, and relationship commitment. Journal of Social and Personal Relationships 23(3):367-86. doi: 10.1177/0265407506064204

Kearns, J. N. \& Fincham, F. D. (2005) Victim and perpetrator accounts of interpersonal transgressions: Self-serving or relationship-serving biases? Personality and Social Psychology Bulletin 31(3):321-33. doi: 10.1177/0146167204271594

Konrath, S., Bushman, B. \& Grove, T. (2009) Seeing my world in a million little pieces: Narcissism, self-construal, and cognitive-perceptual style. Journal of Personality 77(4):1197-228. doi: 10.1111/j.1467-6494.2009.00579.x

Lennon, R. \& Eisenberg, N. (1989) Gender and age differences in empathy and sympathy. In: Empathy and its development, ed. N. Eisenberg \& J. Strayer, pp. 195-217. Cambridge University Press.

Macaskill, A., Maltby, J. \& Day, L. (2002) Forgiveness of self and others and emotional empathy. The Journal of Social Psychology 142(5):663-65. doi: 10.1080/00224540209603925

McCullough, M. E., Emmons, R. A., Kilpatrick, S. D. \& Mooney, C. N. (2003) Narcissists as "victims": The role of narcissism in the perception of transgressions. Personality and Social Psychology Bulletin 29(7):885-93. doi: 10.1177/0146167203029007007

Mullet, E., Neto, F. \& Riviere, S. (2005) Personality and its effects on resentment, revenge, forgiveness, and self-forgiveness. In: Handbook of forgiveness, ed. E. L. Worthington, pp. 159-81. Taylor \& Francis.

Rhodewalt, F. \& Morf, C. C. (1998) On self-aggrandizement and anger: A temporal analysis of narcissism and affective reactions to success and failure. Journal of Personality and Social Psychology 74(3):672-85.

Schumann, K. \& Ross, M. (2010) The benefits, costs, and paradox of revenge. Social and Personality Psychology Compass 4(12):1193-205. doi: 10.1111/j.1751-9004.2010.00322.x

Stillwell, A. M., Baumeister, R. F. \& Del Priore, R. E. (2008) We're all victims here: Toward a psychology of revenge. Basic and Applied Social Psychology 30(3):253-63. doi: 10.1080/01973530802375094 
Stuckless, N. \& Goranson, R. (1992) The vengeance scale: Development of a measure of attitudes toward revenge. Journal of Social Behavior and Personality 7(1):25-42.

Twenge, J. \& Campbell, W. K. (2003) “Isn't it fun to get the respect that we're going to deserve?” Narcissism, social rejection, and aggression. Personality and Social Psychology Bulletin 29(2):261-72. doi: 10.1177/0146167202239051

Twenge, J., Konrath, S., Foster, J., Campbell, W. K. \& Bushman, B. (2008) Egos inflating over time: A cross-temporal meta-analysis of the Narcissistic Personality Inventory. Journal of Personality 76(4):875-902; discussion 903-828. doi: JOPY507 [pii] 10.1111/j.1467-6494.2008.00507.x

Zechmeister, J. S. \& Romero, C. (2002) Victim and offender accounts of interpersonal conflict: Autobiographical narratives of forgiveness and unforgiveness. Journal of Personality and Social Psychology 82(4):675-86.

$<$ Refs end $>$ 